\title{
Dimensional Analysis and Empirical Study on the Cooperation Performance of Competitive Technical Intelligence of R\&D Alliance
}

\author{
Jian-Dong YANG ${ }^{1}$, Hui-Zhi Zou ${ }^{1}$ and Wei HUANG ${ }^{2}$ \\ ${ }^{1}$ China Satellite Maritime Tracking and Control Department, Jiangyin, 214431, China \\ ${ }^{2}$ Management School, Shanghai University of Engineering Science, Shanghai, 201620, China
}

Keywords: R\&D Alliance, CTI, Intelligence Cooperation, Performance.

\begin{abstract}
With the quickening pace of technological innovation, Competitive Technical Intelligence (CTI) plays an increasingly important role in enterprise, industry and national macro strategic planning. As a new area of cooperation, CTI becomes more and more popular in technology innovation alliance. How to display CTI cooperation function and how to enhance CTI cooperation performance have become the hot topic of CI area. This paper gives the dimensions model of value creation and ascending ability, on the basis of alliance performance, intelligence performance and organization cooperation performance, using SPSS and AMOS for factor analysis and validation, so as to provide a scientific basis of constructing the theory system and measuring the intelligence cooperation performance
\end{abstract}

\section{Introduction}

Under the economic globalization historical background with increasingly fierce competitive situation and fast technological innovation, more and more enterprises carry out new technique R\&D, new business and new market exploitation through building $R \& D$ alliance. During strategic cooperation procedure, R\&D alliance should extensively exchange and share CTI in order to effectively implement strategic decision-making, fast knowledge transfer, and technological innovation, which could enhance alliance enterprises' competitive intelligence ability through jointly collecting, analyzing, and utilizing CTI.

In view of the existing literature, current opinions on CI performance primarily all insist on the combination of direct benefit and indirect benefit. By reviewing related literature of CTI cooperation performance, this paper divided CTI cooperation performance into two dimensions of ability enhancement and value creation, then integrated those dimensions with CTI cooperation procedure in order to completely measure CTI cooperation performance using two main lines of information flow and value chain. This paper would further enrich CTI theories and provide basic theory and scientific basis to promote CTI cooperation performance.

\section{Dimensional analysis of CTI cooperation performance}

2.1 Ability enhancement dimension. It is the organization's ability enhancement and function exertion that CTI cooperation performance analysis by organizational capability should focus on. Whether CTI cooperation of R\&D alliance can achieve the alliance's desired efficacy, whether it can enhance information handling and service ability, and whether it can enhance enterprise competitive advantage and core competitiveness are main concern of ability enhancement dimension. Miller J. P. suggested that for achieving competitive advantage, enterprises cannot do without CI work on information sharing, strategic decision-making, organizational reform, enterprise performance, and so on. 
Information collection is primary step of carrying out CTI cooperation activities at which we need to solve these problems: What information should we collect? Where are information sources? What methods should we use to collect? CI sharing is an important aspect of alliance enterprise cooperation, and is also a key bridge and link among organizations. Alliance members can more conveniently learn from each other through resource sharing. The key of CTI cooperation's exerting organizational function lies in realizing knowledge sharing in an alliance through information exchanging and sharing.

It makes organizational learning more convenient and efficient by resources integration, information sharing and constructing platform. The purpose of enterprise's carrying out CTI activities is to raise product competitiveness, market share, and the level of strategic planning and strategic decision-making; the final foothold of R\&D alliance's CTI cooperation lies in raising enterprise's scientific and technological innovation level.

2.2 Value creation dimension. CTI's value includes direct value and indirect value, it also includes economic value and social value. CTI's value depends both on CI itself and on what an alliance uses CI effectively to make decision and puts the decision into effect. In the report for SCIP, Herring J. P. proposed that time saving value, cost reduction, earnings incensement, and other value promotion should all be taken as measurement indexes for intelligence performance. Lönnqvist Antti and Pirttimäki Virpi further pointed out that CI value measurement primarily includes two aspects: value measurement for intelligence itself and CI procedure, i.e., the procedure of intelligence value creation and promotion. Value creation dimension mainly considers and discusses the economic benefit issues of CTI, including CTI cost, information service effect, time benefit of intelligence, potential benefit of intelligence, annual profit growth, etc.

CTI cooperation not only reduces the cost of searching intelligence but also reduces the risks of delay caused by uncertainty and low reliability. The objects and material faced by CTI cooperation activities are just information, and information handling completely depends on person's knowledge, talent and wisdom, so the processing procedure of CTI is entirely a knowledge creation procedure.

The core value of CTI cooperation is knowledge creation value. The purpose of CTI cooperation carried out by R\&D alliance is providing the alliance's strategic decision-making and technology research and development with service and support through intelligence cooperation. And the value of intelligence cooperation directly reflects in the quality and effect of intelligence service. Market economic benefit is the reflection of intelligence's final value.

\section{Research methods}

3.1 Research samples and data collection. Based on the above theoretical derivation of dimension division for CTI cooperation performance, it needs quantitative empirical test in order to more effectively explore and analyses the dimension structure of intelligence cooperation performance. We have mainly adopted questionnaire survey to collect data. The objects of questionnaire are domestic new high-tech enterprises which mainly concentrate in biological medicine, environmental protection and technology, textile and garment, communication technology, information technology, iron, and chemical engineering industries. There are four methods for research data collection: (1)phone call, asking interviewees questions in the questionnaire; (2) e-mail, sending questionnaire to enterprise managers; (3)face-to-face interview; (4)using all kinds of social relations to send questionnaire.

According to statistics standard, sample size shall usually be 5 to 10 times of question number. There are 27 questions in our questionnaire, so the sample size shall be at least 135 . The issuing and receiving situation of this questionnaire survey is shown in Table 1 . The issued questionnaire sum to 436 copies, the received are 372 copies, and the response rate is $85.3 \%$. The valid questionnaires are 358 copies, and the effective rate is $82.1 \%$. 
Tab 1 Summary of questionnaire receiving situation

\begin{tabular}{cccccc}
\hline $\begin{array}{c}\text { Issuing } \\
\text { method }\end{array}$ & $\begin{array}{c}\text { Issuing } \\
\text { amount }\end{array}$ & $\begin{array}{c}\text { Receiving } \\
\text { amount }\end{array}$ & $\begin{array}{c}\text { Response } \\
\text { rate }\end{array}$ & Valid amount & $\begin{array}{c}\text { Effective } \\
\text { rate }\end{array}$ \\
\hline Phone call & 37 & 37 & $100 \%$ & 37 & $100 \%$ \\
E-mail & 76 & 54 & $71.1 \%$ & 48 & $63.2 \%$ \\
$\begin{array}{c}\text { Face-to-face } \\
\text { Social }\end{array}$ & 25 & 25 & $100 \%$ & 22 & $88 \%$ \\
$\begin{array}{c}\text { relations } \\
\text { Sum }\end{array}$ & 436 & 256 & $85.9 \%$ & 251 & $84.2 \%$ \\
\hline
\end{tabular}

The sample interviewees of this study characterize as follows: the majority are in age group of 31-40, the majority's years of working are more than 8 years, the majority specialize in CTI or are middle and senior managers. So the sample mostly consist of managers with rich enterprise work experience, who have clear knowledge of CI, CTI, business goal, development potential, etc. The sample fit this study.

3.2 Measurement indexes. We used Likert 7-stage rating for variable measurement, from "1—totally disagree" to "7—totally agree".

(1) Ability enhancement dimension. According to previous studies, we measured this dimension mainly at these four aspects: information retrieval efficiency, organizational learning ability, intelligence system function, and scientific and technological innovation level, altogether including 14 measurement indexes.

(1)Information retrieval efficiency. According to Langabeer J. R. and Vivian W. Y. Lee's study, we used the following 5 indexes to measure: we judged intelligence universality by approaches for acquiring information source; we cared acquiring intelligence the first time; fact or fiction of intelligence; technical intelligence quality; and the excavation depth of intelligence. (2) Organizational learning ability. Individual vocational study ability is the key of ability enhancement; we cared more about knowledge exchanging and mutual learning in cooperation; and we believed that learning organization construction drove intelligence cooperation performance enhancement obviously. (3) Intelligence system function. Advanced information service system can enhance information work efficiency; providing users with information quickly and efficiently; feedback of information service quality. (4)Scientific and technological innovation level. According to Herring J. P.'s study, we used the following three indexes: it is an important manifestation of the capacity for scientific research to be good at finding problems, raising questions, and establishing research target and direction; project management competence in project $R \& D$ management; innovative thinking.

(2) Value creation dimension. According to former research, we measured this dimension mainly at the following four aspects: intelligence activity cost, intelligence product value, information service effect and economic benefit, altogether including 13 indexes. (1)Intelligence activity cost. According to Kilmetz, Bridge, Lönnqvist Antti, and Pirttimäki Virpi's studies, we used the following three indexes to measure: providing expenditure to encourage staff attending academic exchange and intelligence exchange; paying attention to interpersonal connections and investing to maintain these connections; and investing to create technical conditions and maintain all kinds of intelligence data base. (2)Intelligence product value. According to Craig S. Fleisher and David L. Blenkhorn's study, we used the following three indexes: the quantity and quality of CTI products; influence of CTI research result on leaders' decisions; the economic value of CTI products. (3) Information service effect. Regularly releasing technology monitoring information in alliance or a certain scope; guiding effect of CTI for R\&D and decision; providing different information service content and pattern according to different departments' information demands; the CTI is the important learning content for R\&D group. (4)Economic benefit. According to Jaworski B. and L. C. Wee's study, we used the following three indexes: CTI products are very well transformed at executive level and in R\&D department; CTI drives new product development and market exploitation significantly; corporate profit growth is closely related with CTI work. 


\section{Data analysis}

4.1 Exploratory factor analysis. This paper used SPSS18.0 to examine the reliability and validity of our measurement scale. DeVellis (1991) argued that if reliability coefficient value is above 0.9, then the examination or measurement's reliability is very good; it is all acceptable if above 0.8; if above 0.7, then the scale needs big revision; if below 0.7, then we should redesign the scale. Meanwhile, the Item-Total correlation coefficient of all items kept in the scale cannot be below 0.35. The analysis result shows that except measurement item 5 in Ability enhancement dimension information retrieval efficiency and item 3 in Value creation dimension - intelligence product value have a coefficient below 0.35 , other items' Cronbach's $\alpha$ coefficients are all above 0.7. We deleted those two items, and reexamined the reliability and validity.

The result shows: ability enhancement dimension and value creation dimension's whole Cronbach's $\alpha$ coefficients are both above 0.8, so there is good consistency among the indexes of CTI cooperation performance's dimension structure. Based on the condition that characteristic root $\mu$ value is above 1 and the maximum factor loading coefficient is above 0.5 , we adopted principal component analytical method for factor extraction, adopted maximal square difference for rotation algorithm, and did validity test for the 358 samples. Upon examination, the measurement items' $\mathrm{KMO}$ value is 0.838 , Bartlett spheroidal test statistic value is remarkably different from $0(<0.001)$; we respectively extracted four factors from ability enhancement and value creation dimensions, and the accumulative explained variances are respectively $73.356 \%$ and $76.457 \%$.

Table 2 Factor loading of each item for cooperation performance ability enhancement

\begin{tabular}{|c|c|c|c|c|c|c|c|}
\hline \multirow[b]{2}{*}{ Variable } & \multirow[b]{2}{*}{ Item } & \multicolumn{4}{|c|}{ Factor loading } & \multirow{2}{*}{$\begin{array}{c}\text { Charact. } \\
\text { value }\end{array}$} & \multirow{2}{*}{$\begin{array}{c}\text { Accu. } \\
\text { explai. } \\
\text { varian.(\%) }\end{array}$} \\
\hline & & $\begin{array}{l}\text { inf. } \\
\text { retriev. }\end{array}$ & learn. & system & innova. & & \\
\hline \multirow{5}{*}{$\begin{array}{l}\text { inf. } \\
\text { retriev. }\end{array}$} & $\begin{array}{l}\text { A1(informati. } \\
\text { source) }\end{array}$ & .896 & .085 & .131 & .044 & \multirow{4}{*}{4.926} & \multirow{4}{*}{37.893} \\
\hline & $\begin{array}{l}\text { A2(infor. } \\
\text { collection) }\end{array}$ & .874 & .080 & .051 & .087 & & \\
\hline & $\begin{array}{l}\text { A3(informa. } \\
\text { content) }\end{array}$ & .900 & .081 & .137 & .062 & & \\
\hline & $\begin{array}{l}\text { A4(infor. } \\
\text { excavation) }\end{array}$ & .841 & .127 & .072 & .077 & & \\
\hline & $\begin{array}{l}\text { A5 (individual } \\
\text { learn.) }\end{array}$ & .104 & .833 & .175 & .195 & \multirow{3}{*}{2.441} & \multirow{3}{*}{56.668} \\
\hline \multirow[t]{2}{*}{ learn. } & $\begin{array}{l}\text { A6(cooperation } \\
\text { learn) }\end{array}$ & .109 & .853 & .170 & .093 & & \\
\hline & $\begin{array}{ll}\text { A7 } & \text { (group } \\
\text { learning) }\end{array}$ & .128 & .815 & .243 & .220 & & \\
\hline system & $\begin{array}{l}\text { A8(intellige. } \\
\text { service) }\end{array}$ & .147 & .170 & .805 & .200 & \multirow{3}{*}{1.347} & \multirow{3}{*}{67.027} \\
\hline \multirow{5}{*}{ innova. } & $\begin{array}{l}\text { A9(inte. pushing } \\
\text { spe.) }\end{array}$ & .111 & .213 & .841 & .169 & & \\
\hline & $\begin{array}{l}\text { A10 (service } \\
\text { quality) }\end{array}$ & .088 & .184 & .812 & .125 & & \\
\hline & $\begin{array}{l}\text { A11(tech. project } \\
\text { ch.) }\end{array}$ & .023 & .157 & .189 & .806 & \multirow{3}{*}{1.213} & \multirow{3}{*}{76.358} \\
\hline & $\begin{array}{l}\text { A12(innova. } \\
\text { manage) }\end{array}$ & .104 & .106 & .128 & .835 & & \\
\hline & $\begin{array}{l}\text { A13 } \\
\text { ability) }\end{array}$ & .097 & .197 & .147 & .801 & & \\
\hline
\end{tabular}


Table 3 Factor loading of each item for cooperation performance value creation $(\mathrm{N}=358)$

\begin{tabular}{|c|c|c|c|c|c|c|c|}
\hline Variab. & Item & $\begin{array}{l}\text { inte. } \\
\text { cost }\end{array}$ & $\begin{array}{l}\text { Facto } \\
\text { inte. } \\
\text { value }\end{array}$ & $\begin{array}{l}\text { oading } \\
\text { inte. } \\
\text { effect }\end{array}$ & bene. & $\begin{array}{c}\text { Charact. } \\
\text { value }\end{array}$ & $\begin{array}{c}\text { Accu. } \\
\text { explai. } \\
\text { varian.(\%) }\end{array}$ \\
\hline \multirow{3}{*}{$\begin{array}{l}\text { inte. } \\
\text { cost }\end{array}$} & B1(investme. in training) & .881 & .126 & .105 & .066 & \multirow{3}{*}{4.982} & \multirow{3}{*}{38.325} \\
\hline & B2(cooperation expendi.) & .907 & .091 & .093 & .074 & & \\
\hline & B3 (transfer expenditure) & .911 & .092 & .077 & .076 & & \\
\hline \multirow{3}{*}{$\begin{array}{l}\text { inte. } \\
\text { value }\end{array}$} & B4(inte.quantity\&quality) & .133 & .813 & .176 & .202 & \multirow{3}{*}{1.349} & \multirow{3}{*}{67.438} \\
\hline & B5(intelligence app.value) & .134 & .832 & .190 & .168 & & \\
\hline & B6 (inte. economic value) & .106 & .788 & .191 & .125 & & \\
\hline inte. & B7(tech. direction choice) & .094 & .161 & .815 & .210 & \multirow{3}{*}{1.172} & \multirow{3}{*}{76.457} \\
\hline \multirow[t]{2}{*}{ effect } & B8 (strateg. decision plan) & .104 & .153 & .874 & .084 & & \\
\hline & B9 (R\&D inno. dependi.) & .131 & .286 & .766 & .216 & & \\
\hline \multirow[t]{3}{*}{ bene. } & B10(inte.product transfer) & .026 & .179 & .176 & .830 & \multirow{3}{*}{2.436} & \multirow{3}{*}{57.062} \\
\hline & B11 (market exploitation) & .082 & .131 & .109 & .828 & & \\
\hline & B12 (enter. profit growth) & .139 & .166 & .180 & .813 & & \\
\hline
\end{tabular}

4.2 Confirmatory factor analysis. Based on the former reliability and validity test for the measurement item scale, we used AMOS17.0 to analyse the goodness of fit for dimension structure of CTI cooperation performance. The result is shown in Figure 1. $\chi^{2} / \mathrm{df}$ is 2.566, between 2 and 5, the indexes of fitting GFI, IFI and CFI are all above 0.9, RMSEA is 0.036, below 0.10, these show the good whole fitting of this model.

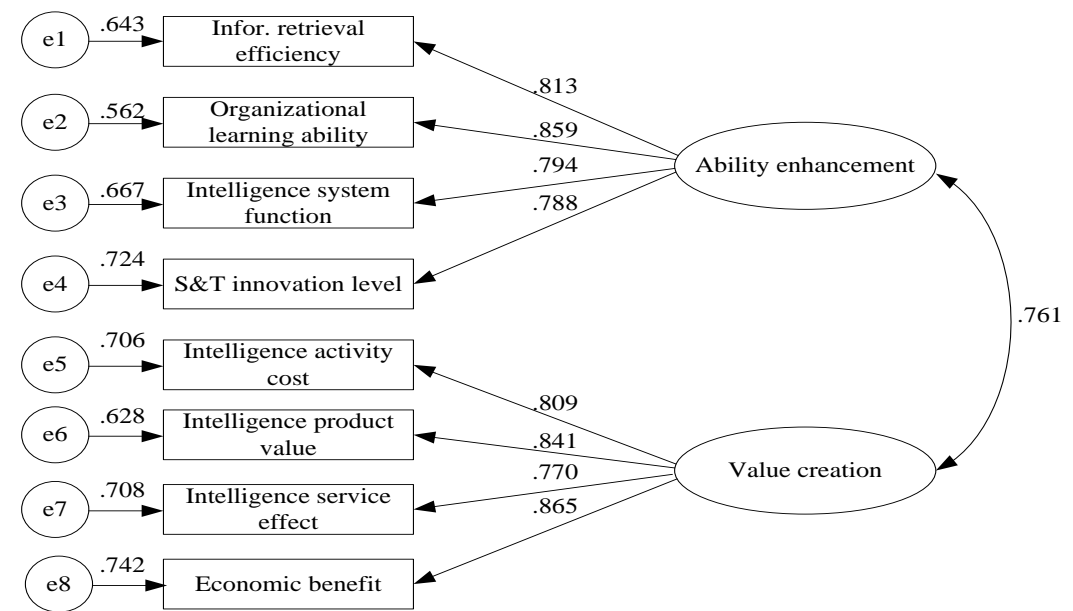

Figure 1 Structural equation model analysis result of CTI cooperation performance dimensionality

\section{Conclusions}

In the era of knowledge economy, information has become an important strategic resource of enterprises and alliances, and enterprises pay high attention to CTI and extensively carry out intelligence cooperation. Based on reviewing literature, and from the perspective of resource ability, this paper innovatively divides CTI cooperation performance into ability enhancement and value creation dimensions according to information flow and value flow in CTI cooperation procedure. We constructed a SEM and a measurement scale, did the questionnaire survey, and used SPSS18.0 and AMOS17.0 to do exploratory and confirmatory factor analyses.

The empirical result shows that the Cronbach's $\alpha$ coefficient of the whole measurement scale is between 0.803 and 0.879 , KMO value is 0.884 , Bartlett's sphericity test statistic is remarkably different from $0(<0.001)$, the model and measured data have good reliability and validity, and the degree of fitting of the model is high. 


\section{References}

[1] Jaworski B., Wee L. C. Competitive Intelligence: Creating Value for the Organization. SCIP Sponsored Research Project, 2013.

[2] Herring J. P. Business intelligence in Japan and Sweden: Lessons for the US [J]. Journal of Business strategy, 2012, 13(2): 44-49.

[3] Fuld L. A recipe for business intelligence success [J]. Journal of Business Strategy, 2011, 12(1): 12-17. 